\title{
Autoantibodies in Connective Tissue Diseases: Clinical Significance and Analysis of Target Autoantigens
}

\author{
Tsuneyo MIMORI
}

\begin{abstract}
Systemic connective tissue diseases are characterized by the production of a number of autoantibodies directed against various cellular constituents. These autoantibodies are closely associated with certain diseases and clinical manifestations, and are therefore useful for clinical practice such as to diagnose diseases and to predict clinical subsets, disease activity and prognosis. To understand the etiology and pathogenic mechanisms of connective tissue diseases, it is particularly important to elucidate the structure and function of target autoantigens recognized by these disease-specific autoantibodies. In recent years, the nature of many target autoantigens have been identified using molecular biology approaches. Most of them are intracellular enzymes and regulatory factors necessary for important biological function involved in gene replication, transcription, RNA processing and protein translation. Thus, the studies of autoantibodies are useful not only in clinical medicine but also in basic cellular and molecular biology.

(Internal Medicine 38: 523-532, 1999)
\end{abstract}

Key words: ribonucleoprotein, deoxyribonucleoprotein, systemic lupus erythematosus, scleroderma, polymyositis/dermatomyositis

\section{Introduction}

Autoantibodies directed against various cellular components are found in sera from connective tissue diseases. These autoantibodies have been demonstrated to be associated with certain diseases and clinical manifestations, and provide us useful information for clinical practice. The development of new technologies for detecting autoantibodies has facilitated identification of more than 50 autoantibodies and their target autoantigens. Most autoantigen molecules are complexes with proteins and RNA (ribonucleoprotein) or DNA (deoxyribonucleoprotein), and act as intracellular enzymes or regulatory factors necessary for important biological function involved in gene replication, transcription, RNA processing and protein translation. Thus, the studies of autoantibodies are useful not only in clinical medicine but also in basic cellular and molecular biology.

The measurement of autoantibodies offers numerous clinical utilities:

1. Marker of diseases: most autoantibodies have high disease specificity and therefore a diagnostic value if they are positive. 2. Marker of disease subsets: most autoantibodies are associated with certain subsets or clinical symptoms of each disease (i.e. anti-dsDNA and lupus nephritis, anti-Scl-70 and diffuse scleroderma, and anti-Jo-1 and myositis with interstitial lung disease).

3. Marker of disease activity: some, but not all, autoantibodies are closely correlated to the disease activity (i.e. anti-dsDNA in SLE, and C-ANCA in Wegener's granulomatosis).

4. Marker of prognosis: certain autoantibodies can be useful to predict the prognosis or severity of diseases (i.e. anti-SRP and severe polymyositis, and anti-RNA polymerases and renal crisis in scleroderma).

Autoantibodies detected in connective tissue diseases are summarized in Table 1. In this review, the clinical significance of these autoantibodies in connective tissue diseases and the nature of their target autoantigens will be discussed.

\section{Autoantibodies in systemic lupus erythematosus (SLE)}

\section{LE factor}

LE factor is autoantibodies against DNA-histone complex and is a serum factor necessary to produce LE cells $(1,2)$. LE cells are observed in vitro when denatured leukocyte nuclei bound to LE factor and complement are ingested by living phagocytic leukocytes. LE factor can also be measured by latex agglutination test, although both specificity and sensitivity

From the Department of Internal Medicine, Keio University School of Medicine, Tokyo

Reprint requests should be addressed to Dr. Tsuneyo Mimori, the Department of Internal Medicine, Keio University School of Medicine, 35 Shinanomachi, Shinjuku-ku, Tokyo 160-8582 
Table 1. Autoantibodies in Connective Tissue Diseases and Their Clinical Significance

Antibodies

1. Autoantibodies in SLE

LE factor
Anti-dsDNA
Anti-Sm

Anti-ribosomal P

Anti-Ki/SL

Anti-PCNA

2. Autoantibodies in SSc

Anti-Scl-70 (Topo I)

Anti-centromere

Anti-U3RNP

Anti-7-2/8-2RNP(Th/To)

Anti-RNA polymerases

3. Autoantibodies in PM/DM

Anti-ARS

Anti-Jo-1

Anti-PL-7

Anti-PL-12

Anti-EJ

Anti-OJ

Anti-AS

Anti-SRP

Anti-Mi-2

4. Autoantibodies in overlap syndrome Anti-U1RNP

Anti-U2RNP

Anti-Ku

Anti-DNA-PKcs

Anti-PM-Scl

5. Autoantibodies in Sjögren's syndrome

Anti-SS-A/Ro

Anti-SS-B/La

6. Autoantibodies in vascular diseases

C-ANCA

Anti-phospholipid

7. Autoantibodies in rheumatoid arthritis Anti-calpastatin

Inhibitor of calpain (72 kDa)
Neutrophil proteinase- 3

Neutrophil myeloperoxidase

$\beta 2$-glycoprotein I

$40-50 \%$
$50-70 \%$
$15-30 \%$
$10 \%$
$10 \%$
$<5 \%$

$$
\begin{array}{r}
20-30 \% \\
20-30 \% \\
5-10 \% \\
5-10 \% \\
6-24 \%
\end{array}
$$

Hystidyl-tRNA synthetase $(50 \mathrm{kDa})$

Threonyl-tRNA synthetase $(80 \mathrm{kDa})$

Alanyl-tRNA synthetase $(110 \mathrm{kDa})$

Glycyl-tRNA synthetase $(75 \mathrm{kDa})$

Isoleucyl-tRNA synthetase

(multienzyme complex)

Asparaginyl-tRNA synthetase

Signal recognition particle

helicase family protein $(218 \mathrm{k} / 240 \mathrm{kDa})$

U1-snRNP (mRNA splicing factor)

U2-snRNP (mRNA splicing factor)

DNA-PK regulatory subunit $(70 \mathrm{k} / 80 \mathrm{kDa})$

DNA-PK catalytic subunit (460 kDa)

20-30\%

$<5 \%$

$<5 \%$

$<5 \%$

$<5 \%$

$$
\begin{array}{r}
? \\
5 \% \\
5-10 \%
\end{array}
$$

$100 \%$ of MCTD

$10-20 \%$

20-30\%

$<5 \%$

8-10\%
Y1-Y5RNP (60 k/52 kDa, Y1-Y5RNA)
RNA polymerase III
termination factor $(48 \mathrm{kDa})$

$50-70 \%$

20-30\%

$50-90 \%$

30-50\%

$10-20 \%$ of SLE etc
Clinical significance

Active SLE, drug-induced lupus

Lupus nephritis, active SLE

CNS lupus, delayed proteinuria

CNS lupus

Sicca syndrome, myopathy

Thrombocytopenia, nephropathy

Diffuse scleroderma

Limited scleroderma

Diffuse scleroderma

Limited scleroderma

Diffuse scleroderma, renal crisis

Anti-synthetase syndrome (pulmonary fibrosis, polyarthritis, inflammatory myopathy)

Severe, refractory PM

DM

MCTD, non-renal SLE, Raynaud's phenomenon

SSc-PM overlap

SSc-PM overlap in Japanese

PM-overlap

SSc-PM overlap in Caucasian

Neonatal lupus, SCLE

Recurrent anular erythema

Wegener's granulomatosis

Microscopic polyangiitis, crescentic gromeluronephritis, Churg-Strauss syndrome, normotensive scleroderma kidney

Anti-phospholipid syndrome (recurrent thrombosis, abortion)

SLE: systemic lupus erythematosus, SSc: systemic sclerosis, PM/DM: polymyositis/dermatomiositis, ARS: aminoacyl-tRNA synthetase, snRNP: small nuclear ribonucleoprotein, DNA-PK: DNA-dependent protein kinase, MCTD: mixed connective tissue disease, CNS: central nervous system, SCLE: subacute cutaneous lupus erythematosus. 
are lower than the classical LE cell phenomenon. In some reports, anti-histone antibodies are thought to also act as LE factor.

LE factor is detected in 40-50\% of active SLE patients and is associated with disease activity. However, LE factor is also detected in other connective tissue diseases, rheumatoid arthritis and chronic active hepatitis, although the frequency is much lower.

\section{Anti-DNA antibodies}

Anti-DNA antibodies are detected in 50-70\% of SLE patients and are correlated to lupus nephritis in particular. Although low-titers of anti-DNA antibodies are sometimes detected in various connective tissue diseases, anti-DNA of high titer $(>50 \mathrm{IU} / \mathrm{ml})$ can be found only in active SLE. Since the titer of anti-DNA is closely correlated to the disease activity, the measurement is very useful to predict the lupus activity and to indicate the treatment.

Both double-strand DNA (dsDNA) and single-strand DNA (ssDNA) are targets of anti-DNA antibodies. However, only anti-dsDNA antibodies are a specific marker of SLE.

Anti-ssDNA can be widely detected in various connective tissue diseases. High-affinity anti-dsDNA antibodies are particularly associated with lupus nephritis. Anti-ssDNA and antidsDNA should be measured simultaneously. Since anti-dsDNA recognizes the phosphate-deoxyribose structure of the DNA molecule, anti-dsDNA can bind to both dsDNA and ssDNA.

It has been reported that anti-DNA antibodies are cross-reactive against various cellular proteins such as cell surface proteins, vimentin, $A$ and $D$ polypeptides of U1RNP and ribosomal S1 proteins $(3,4)$. This fact suggests a possibility that antiDNA antibodies are the polyreactive autoantibodies not only to DNA but also to various antigens, and that the immunogen triggering the production of anti-DNA antibodies is not necessary for DNA itself. Moreover, it has been pointed out that the hypervariable region of anti-DNA shows homology with that of antibodies to certain bacteria, suggesting the possibility of some bacterial infection for anti-DNA production.

It has been widely accepted that circulating DNA-anti-DNA immune complexes are deposited into renal glomeruli and cause inflammation by the activation of complement. However, an alternative hypothesis is proposed in that lupus nephritis may develop by direct interaction of anti-DNA with intrinsic glomerular antigens such as heparan sulfate and laminin which are negatively charged and are cross-reactive with DNA $(5,6)$.

\section{Anti-Sm antibodies}

Anti-Sm antibodies, a specific marker for SLE, are detected in $15-30 \%$ of SLE patients. RNase-resistant anti-ENA antibodies are the same as anti-Sm. The target molecules of antiSm are U1, U2, U4/U6 and U5 small nuclear ribonucleoproteins (snRNP) that play an important role in splicing of premessenger RNA molecules (7). Patient sera with anti-Sm always contain antibodies to U1-RNP, probably because the U1RNP antigen is a part of the Sm antigen and both target molecules have a common structure. Polypeptides termed B'/B,
$\mathrm{D}, \mathrm{E}, \mathrm{F}$ and $\mathrm{G}$ are the common protein components among U1U6 (Sm) snRNPs. Anti-Sm antibodies recognize specifically the $\mathrm{B}^{\prime} / \mathrm{B}$ and $\mathrm{D}$ polypeptides (8).

Anti-Sm antibodies have been reported to be associated with delayed proteinuria, central nervous system involvement and a poor SLE prognosis (9).

\section{Other SLE-specific autoantibodies}

\section{Anti-ribosomal $P$ antibodies}

Autoantibodies to ribosome recognize mainly a common epitope among P0 (38 kDa), P1 (19 kDa) and P2 (17 kDa) proteins of $60 \mathrm{~S}$ ribosomal subunit (10), therefore termed antiribosomal $P$ antibodies. Sera with anti-ribosomal $P$ usually contain antibodies to 28S-ribosomal RNA. In immunofluorescence, nucleolus and cytoplasm are stained by these antibodies. Antiribosomal $\mathrm{P}$ are detected in $10 \%$ of SLE patients. It is noteworthy that they are associated with central nervous system involvement (11).

\section{Anti-Ki/SL antibodies}

Anti-Ki/SL antibodies target an unknown $32 \mathrm{kDa}$ nuclear protein and are found in 10\% of SLE patients. Although the clinical significance is still unclear, an association with sicca syndrome and myopathy have been reported. The function of the $\mathrm{Ki} / \mathrm{SL}$ antigen is unknown, but a sequence homology between the Ki/SL and SV-40 large antigen has been described (12).

\section{Anti-PCNA (proliferating cell nuclear antigen) antibodies}

PCNA is an antigen that is present only in proliferating cells (late G1-S phase of cell cycle) (13). Therefore, autoantibodies to this antigen show a variegated speckled pattern on immunofluorescence, in which only some of the nuclei show positive staining. PCNA is an auxiliary protein necessary for the activation of DNA polymerase $\delta(14)$. Although anti-PCNA is found specifically in SLE, the prevalence is only $1-2 \%$ of SLE patients. Patients with anti-PCNA frequently show renal disease and thrombocytopenia.

\section{Autoantibodies in scleroderma (systemic sclerosis: SSc)}

\section{Anti-Scl-70 (DNA topoisomerase I) antibodies}

Anti-Scl-70 antibodies were first described as autoantibodies to a $70 \mathrm{kDa}$ nuclear protein that were specifically found in scleroderma (15). Later, the target molecule of anti-Scl-70 was elucidated to be DNA topoisomerase I (topo I), an intranuclear enzyme that alters the topology of (or relaxes) supercoiled DNA molecules (16).

Anti-topo I are specifically found in $20-30 \%$ of SSc patients, and are closely associated with diffuse cutaneous involvement and severe pulmonary fibrosis. Respiratory failure due to lung fibrosis is the main cause of death in SSc patients with anti-topo I antibodies. 


\section{Anti-centromere antibodies}

Centromere or kinetocore of chromosomes is the target of autoantibodies in SSc. Anti-centromere antibodies can be detected on immunofluorescence as a discrete speckled pattern of interphase cells and chromosome-associated staining in mitotic cells (17). The main target molecules are three centromere proteins termed CENP-A (17 kDa), CENP-B (80 kDa) and CENP-C (140 kDa) (18).

Anti-centromere antibodies are detected in $20-30 \%$ of SSc patients, but are also found in primary Raynaud's disease, Sjögren's syndrome and primary biliary cirrhosis. Anti-centromere antibodies are associated with limited cutaneous involvement or CREST syndrome and have been reported to be associated with pulmonary hypertension in Caucasian patients.

\section{Anti-nucleolar antibodies}

Anti-nuclear antibodies that show nucleolar staining on immunofluorescence are relatively specific for SSc. Recently, some target nucleolar antigens were identified.

\section{Anti-RNA polymerase antibodies}

Autoantibodies to RNA polymerase I were first described as a rare anti-nucleolar antibody system in SSc (19). Recently, it was demonstrated that these autoantibodies recognized not only RNA polymerase I, but also RNA polymerases II and III. These autoantibodies show heterogeneous reactivity against each class of polymerases such as polymerases I+II+III, polymerase II and polymerase III (20-22). These autoantibodies can be detected by only the protein-immunoprecipitation assay using ${ }^{35} \mathrm{~S}$-methionine-labeled HeLa cells, in which a characteristic set of proteins (13 polypeptides ranging from $210 \mathrm{k}$ to $14 \mathrm{kDa}$ ) can be seen.

An ethnic background has been described. Anti-RNA polymerases are frequently found in Caucasian patients with SSc (24\%) but are rare in Japanese patients (6\%). However, patients with these antibodies in both ethnic groups reveal diffuse cutaneous involvement, a low prevalence of lung fibrosis and a high prevalence of renal crisis.

\section{Anti-U3RNP (fibrillarin) antibodies}

U3RNP is a complex of U3RNA and a $34 \mathrm{kDa}$ protein termed "fibrillarin" that is localized in the nucleolus and is thought to be involved in the processing of ribosomal RNA (23). The RNA- immunoprecipitation assay is necessary to detect antiU3RNP antibodies.

Autoantibodies to U3RNP are detected in 5-10\% of Japanese patients with SSc. African American and Latin American patients are reported to reveal a higher reactivity (20-40\%) to U3RNP. Anti-U3RNP are associated with diffuse cutaneous scleroderma but not with obvious internal organ involvements (24).

\section{Anti-7-2/8-2RNP (Th/To) antibodies}

Autoantibodies that immunoprecipitate two classes of small nucleolar RNAs, 7-2RNA (or 7SM-RNA) and 8-2RNA (or H1RNA), are found in patients with scleroderma. These autoanti- bodies are also called anti-Th or anti-To antibodies. 8-2RNA is RNase $\mathrm{P}$ that is involved in the processing of transfer RNAs (25), and 7-2RNA is identical with RNase MRP that is involved in the processing of mitochondria primer RNA (26). The 40 $\mathrm{kDa}$ protein, a common protein component of these ribonucleoprotein complexes is the main target of autoantibodies.

Anti-7-2/8-2RNP antibodies are detected in 5\% of scleroderma patients and are correlated with limited cutaneous involvement. Some patients with only Raynaud's phenomenon may develop sclerodermatous skin changes if they have anti7-2/8-2RNP antibodies (24).

\section{Autoantibodies in Polymyositis/Dermatomyositis (PM/DM)}

\section{Autoantibodies to aminoacyl-tRNA synthetases}

Aminoacyl-tRNA synthetases (ARS) are the enzymes that catalyze the binding of amino acids to their corresponding tRNAs under the presence of ATP. Aminoacyl-tRNA synthetases are the major targets of autoimmunity in PM/DM. Six classes of autoantibodies reacting with ARS have been recognized to date; anti-Jo-1 (histidyl), anti-PL-7 (threonyl), antiPL-12 (alanyl), anti-EJ (glycyl), anti-OJ (isoleucyl) and antiKS (asparaginyl). Patients with these autoantibodies reveal a similar clinical feature of polymyositis, polyarthropathy and pulmonary fibrosis (so-called "anti-synthetase syndrome") despite their different immunological specificities.

\section{Anti-Jo-1 (histidyl-tRNA synthetase) antibodies}

Anti-Jo-1 antibodies are the first well-characterized autoantibodies in PM/DM, and are the most common myositis-specific autoantibodies found in $20-30 \%$ of PM/DM patients in all ethnic and geographic populations $(27,28)$. Although antiJo-1 is detected by standard Ouchterlony double immunodiffusion, it can also be detected by immunoprecipitation assay in which sera containing anti-Jo-1 immunoprecipitate a distinct tRNA for histidine ( $\mathrm{tRNA}^{\mathrm{His}}$ ) and a $50 \mathrm{kDa}$ protein from HeLa cell extracts. The identification of the Jo-1 antigen as histidyl-tRNA synthetase was demonstrated by the evidence that anti-Jo-1 antibodies immunoprecipitated tRNA for histidine (tRNA containing anticodon for histidine) along with a $50 \mathrm{kDa}$ immunoreactive protein dimer (29), and IgG from sera containing anti-Jo-1 specifically inhibited the binding of histidine to the corresponding tRNA (30).

Patients with anti-Jo-1 reveal the characteristic clinical manifestations. These features include polymyositis, chronic pulmonary fibrosis, polyarthritis, and although less frequent, Raynaud's phenomenon $(28,31,32)$. Pulmonary fibrosis is likely to precede myositis in some patients, and vice versa in other patients (31). Therefore, the presence of anti-Jo-1 appears to be a predicting marker of the disease.

\section{Other autoantibodies to aminoacyl-tRNA synthetases}

Five classes of autoantibodies reacting with ARS, as well as anti-Jo-1, are identified. Although the frequency of these autoantibodies in myositis patients is less than that of anti-Jo-1 
(2-5\% of PM/DM respectively), patients with these autoantibodies reveal similar clinical manifestations which are found in patients with anti-Jo-1 antibodies, such as myositis, polyarthropathy and pulmonary fibrosis. These syndromes characterized by autoantibodies to ARS are designated as "antisynthetase syndrome". However, recent clinical studies also show that the clinical manifestations seem to be slightly different among patient groups having these autoantibodies.

Anti-PL-7 (threonyl-tRNA synthetase): Anti-PL-7 antibodies are the second anti-ARS that immunoprecipitate tRNA for threonine (tRNA ${ }^{\mathrm{Th}}$ ) and a $80 \mathrm{kDa}$ protein of threonyl-tRNA synthetase (33). The clinical features of patients with anti-PL7 are quite similar to those with anti-Jo-1 (34).

Anti-PL-12 (alanyl-tRNA synthetase): Sera with anti-ARS immunoprecipitate distinct tRNAs but most sera do not recognize directly the tRNA itself. However, anti-PL-12 antibodies are an exception to this point, since such patient sera also contain antibodies that recognize directly the tRNA for alanine (tRNA ${ }^{\text {Ala }}$ ) along with a $110 \mathrm{kDa}$ protein of alanyl-tRNA synthetase (35). Although it was believed that anti-PL-12 is associated with myositis and pulmonary fibrosis (36), a recent report suggests that anti-PL-12 appears to correlate more strongly to interstitial lung disease without myositis (37).

Anti-OJ (isoleucyl-tRNA synthetase): The major target antigen of anti-OJ antibodies are isoleucyl-tRNA synthetase, but anti-OJ antibodies also recognize other synthetases. Although other autoantibodies to five classes of ARS recognize independent single proteins, only anti-OJ react with a multi-enzyme complex organized by 10 polypeptides that appear to include ARS activities for 9 amino acid systems (38).

Anti-EJ (glycyl-tRNA synthetase): Anti-EJ antibodies recognize glycyl-tRNA synthetases. Most sera containing anti-EJ immunoprecipitate a $75 \mathrm{kDa}$ protein of glycyl-tRNA synthetase along with 4 associated tRNAs (39).

Anti-KS (asparaginyl-tRNA synthetase): A new class of autoantibodies to aminoacyl tRNA synthetases, termed anti-KS that recognized asparaginyl-tRNA synthetase, was recently described (40). Unlike other anti-synthetases, anti-KS antibodies were detected only in patients with idiopathic interstitial pneumonitis without myositis (40).

\section{Autoantibodies to signal recognition particle (SRP)}

Signal recognition particle (SRP) is a cytoplasmic small RNA-protein complex that consists of 7SL-RNA and 6 polypeptides of $72 \mathrm{k}, 68 \mathrm{k}, 54 \mathrm{k}, 19 \mathrm{k}, 14 \mathrm{k}$, and $9 \mathrm{kDa}$. The biological function of SRP is to recognize signal sequences in $\mathrm{N}$-termini of secretary proteins or membrane proteins via binding to the $54 \mathrm{kDa}$ subunit and to regulate the translocation of newly synthesized proteins across the endoplasmic reticulum membrane.

Some patients (about 5\%) of PM/DM produce autoantibodies to $\operatorname{SRP}(27,41)$. Anti-SRP antibodies recognize mainly the $54 \mathrm{kDa}$ subunit that is involved in binding to signal sequences of newly synthesized proteins as well as the SRP receptor on the endoplasmic reticulum. However, the $72 \mathrm{k}$ and $9 \mathrm{kDa}$ subunits are also recognized by sera containing anti-SRP antibodies.
It is noted that patients with anti-SRP reveal severe myositis with a relatively acute onset. These patients are usually resistant to standard treatment by corticosteroids and show frequent exacerbation (41). Unlike anti-ARS, skin rashes of DM, pulmonary disease, arthritis and Raynaud's phenomenon are infrequent in patients with anti-SRP.

\section{Anti-Mi-2 antibodies}

Anti-Mi-2 antibodies are more common in DM than in PM and therefore appear to be a marker for DM. Anti-Mi-2 antibodies are detected in $8 \%$ of all myositis patients and in 15$20 \%$ of DM patients (42). Unlike other myositis-specific autoantibodies, anti-Mi-2 antibodies are also found in juvenile DM.

Several recent reports have clarified the nature of the Mi-2 antigen. Seelig et al demonstrated by molecular cloning that the target antigen was a $218 \mathrm{kDa}$ nuclear protein encoded on chromosome 12 and belonged to the SNF/RAD 54 helicase family (43). They isolated a cDNA clone encoding $6.4 \mathrm{~kb}$ that hybridized the $6.8 \mathrm{~kb}$ poly $(\mathrm{A})^{+}$RNA. This cDNA encoded a polypeptide of 1,912 amino acids with a calculated molecular weight of 217,989 . This cDNA had a sequence homology at the amino acid level to various helicases. Helicases are the enzymes that are thought to be involved in genomic replication, expression, repair and chromosome segregation.

Ge et al reported independently the molecular cloning of the Mi-2 antigen (44). They isolated a cDNA clone containing a $1,589 \mathrm{bp}$ insert that hybridized to a single $7.5-8.0 \mathrm{~kb}$ mRNA of Hela cells by Northern blot. The sequence contained four potential zinc-finger motifs and several charged regions. However, only one of five anti-Mi-2 sera reacted with the recombinant protein in vitro expressed from the cDNA, suggesting that a major common epitope might be conformational in nature. They claimed that the $240 \mathrm{kDa} \mathrm{Mi}-2$ protein was a novel protein, and showed similarity to a sequence tag from a cDNA derived from human brain (EST03869, clone HFBDK47) of unknown function.

It has been recently identified that both cDNAs for the Mi2 major antigen reported by the two investigators are different, but they belong to the same group of the human helicase family.

\section{Autoantibodies in overlap syndrome}

\section{Anti-U1RNP antibodies}

Antibodies to U1RNP, formerly known as anti-RNP or antinRNP antibodies, are widely detected in various connective tissue diseases and even in unclassified connective tissue disease. However, patients with overlapping SLE, scleroderma and PM/DM most frequently have anti-U1RNP antibodies. In particular, patients with a high titer of anti-U1RNP antibodies but not with anti-Sm are diagnosed as having mixed connective tissue disease (MCTD).

U1RNP is a complex of U1 small nuclear RNA and 9 polypeptides termed $70 \mathrm{~K}(70 \mathrm{kDa}), \mathrm{A}(34 \mathrm{kDa}), \mathrm{B}^{\prime} / \mathrm{B}(29 \mathrm{k} / 28$ $\mathrm{kDa}), \mathrm{C}(22 \mathrm{kDa}), \mathrm{D}(16 \mathrm{kDa}), \mathrm{E}(13 \mathrm{kDa}), \mathrm{F}(12 \mathrm{kDa})$ and $\mathrm{G}$ 
$(11 \mathrm{kDa})$, which is involved in the splicing of pre-mRNA (7). $\mathrm{B}^{\prime} / \mathrm{B}$ and D-G polypeptides are the common components of Sm snRNPs (U1-U6RNP). The $70 \mathrm{~K}, \mathrm{~A}$ and $\mathrm{C}$ polypeptides are the main targets of anti-U1RNP antibodies (8).

\section{Anti-U2RNP antibodies}

Autoantibodies to U2RNP that recognize U2RNP-specific $\mathrm{A}^{\prime}$ and $\mathrm{B}^{\prime \prime}$ polypeptides have been identified (45). Since the B" polypeptide has a common amino acid sequence with the U1RNP-A polypeptide, autoantibodies reactive with the B" epitope also recognize U1RNP molecule (46).

Both anti-U2RNP $\left(\mathrm{A}^{\prime}\right)$ and anti-U1/U2RNP (B") antibodies are specifically found in patients with scleroderma and elevated serum myogenic enzymes (47). These autoantibodies can only be detected by RNA-immunoprecipitation assay.

\section{Autoantibodies to $K u(p 70 / p 80)$ and DNA-dependent protein kinase (DNA-PK)}

Anti-Ku antibodies were first described in patients with polymyositis-scleroderma overlap syndrome in the Japanese population (48). However, the same autoantibodies were described later in the Caucasian population in patients with mainly SLE.

The target antigen of anti-Ku antibodies is a heterodimer of $70 \mathrm{kDa}$ and $80 \mathrm{kDa}$ proteins (p70/p80) that binds selectively to the ends of double-strand DNA $(49,50)$. Recently, the Ku protein was identified as a regulatory subunit of DNA-dependent protein kinase (DNA-PK) $(51,52)$. DNA-PK consists of an $460 \mathrm{kDa}$ catalytic subunit ( 460 or DNA-PKcs, formerly known as p350) and the regulatory component $\mathrm{Ku}(\mathrm{p} 70 / \mathrm{p} 80$ ), and catalyzes phosphorylation of many nuclear proteins including nuclear enzymes and transcription factors under the presence of DNA fragments. Once bound to double-strand DNA, the $\mathrm{Ku}$ protein creates a binding site for DNA-PKcs and assembles the DNA-PK holoenzyme. More recently, it has been demonstrated that this enzyme complex is involved in DNA repair and $\mathrm{V}(\mathrm{D}) \mathrm{J}$ recombination (53-55). It has also been suggested that the defect of the gene encoding DNA-PKcs may be a cause of SCID mouse $(56,57)$. The cDNA encoding for DNA-PKcs was isolated by molecular cloning, and was identified to have structural similarities to the phosphatidyl inositol-3-kinase and the product of the ataxia-teleangiectasia gene (58).

New autoantibodies directed against the $460 \mathrm{kDa}$ DNA-PKcs have been described. Suwa et al reported autoantibodies to DNA-PKcs in 10 patients that could be detected by protein immunoprecipitation technique (59). Six out of ten sera with anti-DNA-PKcs simultaneously contained anti-Ku antibodies, suggesting that relatively intact forms of the DNA-PK complex may act as autoantigenic particles to trigger the autoimmune response in selected patients. Autoantibodies to DNAPKcs were found mainly in patients with PM or PM-scleroderma overlap syndrome.

\section{Anti-PM-Scl antibodies}

Anti-PM-Scl antibodies, initially referred to anti-PM-1 and later separated from several specificities, are closely associated with Caucasian patients with myositis-scleroderma over- lap syndrome (60). It has been reported that almost $50 \%$ of patients with anti-PM-Scl have myositis-scleroderma and about $25 \%$ of the patients with this syndrome have the antibodies (61). However, anti-PM-Scl antibodies are not found in Japanese patients with myositis overlap syndrome (28). One of the reasons for the ethnic discrepancy of anti-PM-Scl appears to be attributed to the genetic background. Anti-PM-Scl are strongly associated with HLA-DR3 haplotype that is found in $75-100 \%$ of patients with anti-PM-Scl but in 30\% of the normal Caucasian population (61). In Japanese, HLA-DR3 is only found in less than $1 \%$ of the normal population.

The PM-Scl antigen is a nucleolar and nuclear antigen complex that consists of at least 11 polypeptides (60) or, in other study, 16 polypeptides ranging from $110 \mathrm{kDa}$ to $20 \mathrm{kDa}(62)$. The biological function of the PM-Scl is not known. Since the $\mathrm{PM}-\mathrm{Scl}$ antigen is mainly located in the granular component of nucleoli which is known to be the site of ribosomal assembly and packaging, this antigen complex may be involved in pre-ribosomal particle assembly (60).

\section{Autoantibodies in Sjögren's Syndrome}

\section{Anti-SS-B/La antibodies}

Anti-SS-B/La antibodies are the highly specific marker autoantibodies found in 20-30\% of primary Sjögren's syndrome patients. Although anti-SS-B/La can be also detected in 5-10\% of SLE patients, such patients always reveal sicca symptoms (secondary Sjögren's syndrome). Recently, an association with recurrent annular erythema has been reported in patients with anti-SS-B/La antibodies (63). Patient sera with anti-SS-B/La consistently contain anti-SS-A/Ro antibodies.

The target antigen of anti-SS-B/La is a $48 \mathrm{kDa}$ nuclear protein bound to various small RNAs such as tRNA precursors, ribosomal 5S-RNA precursor, 7S-RNAs and Y1-Y5RNAs (64). All of these SS-B/La-associated RNAs are the transcription products of RNA polymerase III, and therefore it has been estimated that the SS-B/La protein is the termination factor of RNA polymerase III that is involved in terminating the polymerase reaction and increasing the efficacy of transcription (65).

\section{Anti-SS-A/Ro antibodies}

Anti-SS-A/Ro antibodies are detected in $50-70 \%$ of patients with primary Sjögren's syndrome. However, since anti-SS-A/ Ro can be widely found in patients with other connective tissue diseases, they are not as highly specific for Sjögren's syndrome as anti-SS-B/La antibodies. Anti-SS-A/Ro are rather important as a marker of neonatal lupus and subacute cutaneous lupus erythematosus. Neonatal babies whose mothers have anti-SS-A/Ro may develop rash, cytopenia, liver dysfunction and congenital heart block. These conditions are known as neonatal lupus syndrome, and are thought to be developed by maternal (IgG-type) anti-SS-A/Ro antibodies that pass through the placenta during pregnancy (66).

The target antigen of anti-SS-A/Ro is $60 \mathrm{kDa}$ and $52 \mathrm{kDa}$ proteins associated with five cytoplasmic small RNAs (Y1Y5RNA) (67-69). Since Y-RNAs are the transcription prod- 
ucts of RNA polymerase III and are bound to La/SS-B protein, at least some of SS-B/La and SS-A/Ro antigens are located on the same complex molecule via Y-RNAs. The biological function of SS-A/Ro antigen has been unknown, but recently it was proposed that the SS-A/Ro protein might be involved in the quality control or discard pathway of 5S-ribosomal RNA (70).

\section{Autoantibodies in Vasculitis Syndrome and Vascular Diseases}

\section{Anti-neutrophil cytoplasmic antibodies (ANCA)}

It was thought long time that autoantibodies were not found in patients with necrotizing vasculitides such as polyarteritis nodosa. However, once ANCAs (anti-neutrophil cytoplasmic antibodies) were discovered (71), they were recognized as marker antibodies of certain vasculitis syndromes (72). In indirect immunofluorescence using ethanol-fixed human granulocytes as antigen substrates, C-ANCA (stains whole cytoplasm) and P-ANCA (stains only perinuclear cytoplasm) are distinguished by their staining patterns.

C-ANCA (PR3-ANCA) is highly specific for Wegener's granulomatosis. C-ANCA can be detected in $50-80 \%$ of the patients with acute phase Wegener's granulomatosis, and the titer is correlated to the disease actitivity $(73,74)$. The target molecule of C-ANCA is proteinase-3 (PR-3), the $23 \mathrm{kDa}$ serine proteinase localized in alpha granules of neutrophils.

P-ANCA (MPO-ANCA) is detected in patients with microscopic polyarteritis, idiopathic crescentic glomerulonephritis and, less frequently, allergic angiitis and granulomatosis (Churg-Strauss syndrome) (74, 75). Recently, P-ANCA was also reported to be associated with normotensive renal crisis in SSc patients (76). Myeloperoxidase (MPO) in neutrophils is the main target molecule of P-ANCA in these vasculitides. However, atypical P-ANCAs are sometimes detected in patients with rheumatoid arthritis and inflammatory bowel diseases. In these cases, neutrophil-cytoplasmic antigens such as cathepsin-G, lactoferrin and elastase, and nuclear antigens such as HMG-1 and 2 have been reported to be their target molecules (77).

\section{Anti-phospholipid antibodies (APA)}

Anti-phospholipid antibodies (APA) are a generic term of autoantibodies that react negative-charged phospholipids such as cardiolipin and phosphatidyl serine. Lupus anticoagulant and BFP are included in the category of APA. Patients with APA frequently reveal repetitive thrombotic events of the artery and vein, such as deep vein thrombosis, cerebral infarction, pulmonary embolism and habitual abortion by palacental infarction. These conditions are known as "anti-phospholipid syndrome (APS)" (78). APS is sometimes found in patients with SLE (secondary APS), but are also found in apparently "healthy" individuals (primary APS).

Recently, it was noted that a serum factor is necessary for the binding between APA and phospholipid, and that $\beta 2$-glycoprotein I ( $\beta 2-\mathrm{GPI})$ is one of the serum factors. $\beta 2-\mathrm{GPI}$ changes its conformation and the epitope is exposed when $\beta 2$ -
GPI binds to phospholipids (79). Such APA is now called $\beta 2$ GPI-dependent APA.

\section{Autoantibodies in Rheumatoid Arthritis}

\section{Anti-calpastatin antibodies}

Calpastatin is an endogenous inhibitor protein of the calcium-dependent neutral proteinase, calpain. We as well as Canadian investigators described independently the presence of autoantibodies to calpastatin in patients with systemic rheumatic diseases $(80,81)$.

There have been several reports suggesting that calpain may be involved in activating inflammatory processes and pathogenic mechanisms of rheumatic disorders. That is; 1) calpain is increased in synovial cells and is secreted into synovial fluid of rheumatic patients, 2) calpain degrades cartilage proteoglycan, 3) calpain activates and secretes IL-1 $\alpha$ through processing its precursor molecules, 4) autodigestion of calpain generates an oligopeptide which acts as a chemotactic factor, and 5) calpain irreversibly activates protein kinase C, a key enzyme of signal transduction. We demonstrated that IgG from patient sera containing anti-calpastatin antibodies specifically inhibited the biological function of calpastatin and therefore increased the proteolytic activity of calpain (80). This finding supports the hypothesis that autoantibodies to calpastatin may play a role in tissue destruction and activation of inflammation through increasing calpain activity in tissues.

Anti-calpastatin antibodies were detected in 45-57\% of patients with rheumatoid arthritis in both reports. However, Despres et al described that the antibodies are exclusively found in RA patients (81), whereas we found that the antibodies were also detected in 20-30\% of other systemic rheumatic diseases (80). The true disease specificity and clinical significance of anti-calpastatin antibodies remain to be determined.

\section{Etiology and Pathogenic Mechanisms of Autoantibodies}

The production of disease-specific autoantibodies may closely correlate to etiopathogenic mechanisms of connective tissue diseases. Neonatal lupus syndrome may be a good example to demonstrate that autoantibodies can be pathogenic in a certain condition, although the mechanism is still unclear. Another example is anti-synthetase syndrome. Patients with antibodies to different aminoacyl tRNA synthetases (ARS) reveal the same clinical symptoms known as anti-synthetase syndrome, despite the fact that each ARS molecule is immunologically distinct. This fact may suggest that the immune response to molecules with analogous functions leads a similar clinical syndrome. However, there has been no evidence that anti-ARS autoantibodies penetrate into living cells and directly inhibit the function of ARS in vivo. One possible hypothesis is that several myogenic viruses might interact with ARS and that different virus-ARS complexes act as antigens to disrupt the tolerance to self-antigens. In fact, certain RNA virus genomes have tRNA-like structures and can be aminoacylated by ARS 
(30). There are many findings suggesting that picornaviruses (particularly Coxsackie B virus) might be the causative agents of myositis in children (82). However, this hypothesis appears to have a disadvantage since anti-ARS are found in adults but are rarely found in child myositis.

An alternative hypothesis is that molecular mimicry between autoantigen molecules and infectious agents might produce cross-reactive autoantibodies. Many instances of molecular mimicry between myositis-related autoantigens and viral proteins have been reported (83-89). Once anti-viral antibodies cross-reacting with an autoantigen epitope are produced, B cells which have immunoglobulin receptor to the common epitope bind autoantigen molecules and act as antigen-presenting cells against autoreactive $\mathrm{T}$ cells. The activated autoreactive $\mathrm{T}$ cells in turn stimulate autoantibody-producing B cells. Thus, epitopes on autoantigen molecules will be expanding $(90,91)$.

\section{References}

1) Hargraves MM, Richmond $\mathrm{H}$, Morton R. Presentation of two bone marrow elements. The "tart" cell and the "LE" cell. Proc Staff Meet Mayo Clin 23: 23-28, 1948.

2) Holman H, Deicher HR. The reaction of the lupus erythematosus (L.E.) cell factor with deoxyribonucleoprotein of the cell nucleus. J Clin Invest 38: 2059-2072, 1959.

3) Reichlin M, Martin A, Taylor-Albert E, et al. Lupus autoantibodies to native DNA cross-react with the A and D snRNP polypeptides. J Clin Invest 93: 443-449, 1994.

4) Tsuzaka K, Leu AK, Frank MB, et al. Lupus autoantibodies to double stranded DNA cross-react with ribosomal protein S1. J Immunol 156: 1668-1675, 1996.

5) Faaber P, Rijke TPM, van de Putte LBA, Capel PJ, Berden JH. Crossreactivity of human and murine anti-DNA antibodies with heparan sulfate. The major glycosaminoglycan in glomerular basement membranes. J Clin Invest 77: 1824-1830, 1986.

6) Sabbaga J, Line SRP, Potocnjak P, Madaio MP. A murine nephritogenic monoclonal anti-DNA antibody binds directly to mouse laminin, the major non-collagenous protein component of the glomerular basement membrane. Eur J Immunol 19: 137-143, 1989.

7) Lerner MR, Steitz JA. Antibodies to small nuclear RNAs complexed with proteins are produced by patients with systemic lupus erythematosus. Proc Natl Acad Sci USA 76: 5495-5499, 1979.

8) Pettersson I, Hinterberger M, Mimori T, Gottlieb E, Steitz JA. The structure of mammalian small nuclear ribonucleoproteins. Identification of multiple protein components reactive with anti-(U1) ribonucleoprotein and anti-Sm autoantibodies. J Biol Chem 259: 5907-5914, 1984.

9) Homma M, Mimori T, Takeda Y, et al. Autoantibodies to the Sm antigen: immunological approach to clinical aspects of systemic lupus erythematosus. J Rheumatol 14(Suppl 13): 188-193, 1987.

10) Francoeur A-M, Peebles CL, Heckman KJ, Lee JC, Tan EM. Identification of ribosomal protein autoantigens. J Immunol 135: 2378-2384, 1985.

11) Bonfa E, Golombek SJ, Kaufman LD, et al. Association between lupus psychosis and anti-ribosomal P protein antibodies. N Engl J Med 317: 265-271, 1987.

12) Yamanaka $K$, Takasaki $Y$, Nishida $Y$, Shimada $K$, Shibata M, Hashimoto $\mathrm{H}$. Detection and qualification of anti-Ki antibodies by enzyme-linked immunosorbent assay using recombinant Ki antigen. Arthritis Rheum 35: 667-671, 1992.

13) Miyachi K, Fritzler MJ, Tan EM, et al. Autoantibody to a nuclear antigen in proliferating cells. J Immunol 121: 2228-2234, 1978.

14) Prelish G, Tan CK, Kostura M, et al. Functional identity of proliferating nuclear antigen and a DNA polymerase- $\delta$ auxiliary protein. Nature 326: $517-520,1987$.
15) Douvas AS, Achten M, Tan EM. Identification of a nuclear protein (Scl70) as a unique target of human antinuclear antibodies in scleroderma. $\mathrm{J}$ Biol Chem 254: 10514-10522, 1979.

16) Shero JH, Bordwell B, Rothfield NF, Earnshaw WC. High titers of autoantibodies to topoisomerase I ( $\mathrm{Scl}-70)$ in sera from scleroderma patients. Science 231: 737-740, 1986.

17) Moroi Y, Peebles C, Fritzler MJ, Steigerwald J, Tan EM. Autoantibody to centromere (kinetocore) in scleroderma sera. Proc Natl Acad Sci USA 77: 1627-1631, 1980.

18) Earnshaw WC, Bordwell B, Marino C, Rothfield N. Three human chromosomal autoantigens are recognized by sera from patients with anticentromere antibodies. J Clin Invest 77: 426-430, 1986.

19) Reimer G, Rose KM, Scheer U, Tan EM. Autoantibodies to RNA polymerase I in scleroderma sera. J Clin Invest 79: 65-72, 1987.

20) Kuwana M, Kaburaki J, Mimori T, Tojo T, Homma M. Autoantibody reactive with three classes of RNA polymerases in sera from patients with systemic sclerosis. J Clin Invest 91: 1399-1404, 1993.

21) Hirakata M, Okano Y, Pati U, et al. Identification of autoantibodies to RNA polymerase II. Occurrence in systemic sclerosis and association with autoantibodies to RNA polymerases I and III. J Clin Invest 91: 26652672, 1993.

22) Okano Y, Steen VD, Medsger TA Jr. Autoantibody reactive with RNA polymerase III in systemic sclerosis. Ann Intern Med 119: 1005-1013, 1993.

23) Lischwe MA, Ochs RL, Reddy R, et al. Purification and partial characterization of a nucleolar scleroderma antigen $(\mathrm{Mr}=34,000 ; \mathrm{pI}, 8.5)$ rich in $\mathrm{N}^{\mathrm{G}}, \mathrm{N}^{\mathrm{G}}$-dimethylarginine. J Biol Chem 260: 14304-14310, 1985.

24) Kuwana M, Mimori T, Hama N, Kaburaki J, Okano Y, Tojo T. Clinical significance of anti-nucleolar antibodies detected by immunoprecipitation assays in sera from patients with systemic sclerosis. Jpn J Rheumatol 4: 265-275, 1993.

25) Gold HA, Craft J, Hardin JA, Bartkiewicz M, Altman S. Antibodies in human serum that precipitate ribonuclease P. Proc Natl Acad Sci USA 85: 5483-5487, 1988.

26) Gold HA, Topper JN, Clayton DA, Craft J. The RNA processing enzyme RNase MRP is identical to the Th RNP and related to RNase P. Science 245: 1377-1380, 1989.

27) Nishikai M, Reichlin M. Heterogeneity of precipitating antibodies in polymyositis and dermatomyositis. Characterization of the Jo-1 antibody system. Arthritis Rheum 23: 881-888, 1980.

28) Hirakata M, Mimori T, Akizuki M, Craft J, Hardin JA, Homma M. Autoantibodies to small nuclear and cytoplasmic ribonucleoproteins in Japanese patients with inflammatory muscle disease. Arthritis Rheum 35: 449456, 1992.

29) Rosa MD, Hendrick JP Jr, Lerner MR, Steitz JA, Reichlin M. A mammalian tRNA $^{\text {His }}$-containing antigen is recognized by the polymyositis-specific antibody anti-Jo-1. Nucleic Acid Res 11: 853-870, 1983.

30) Mathews MB, Bernstein RM. Myositis autoantibody inhibits histidyltRNA synthetase: a model for autoimmunity. Nature 304: 177-179, 1983.

31) Yoshida S, Akizuki M, Mimori T, Yamagata H, Inada $S$, Homma M. The precipitating antibody to an acidic nuclear protein antigen, the Jo-1, in connective tissue diseases. A marker for a subset of polymyositis with interstitial pulmonary fibrosis. Arthritis Rheum 26: 604-611, 1983.

32) Oddis CV, Medsger TA Jr, Cooperstein LA. A subluxing arthropathy associated with the anti-Jo-1 antibody in polymyositis/dermatomyositis. Arthritis Rheum 33: 1640-1645, 1990.

33) Mathews MB, Reichlin M, Hughes GRV, Bernstein RM. Anti-threonyltRNA synthetase, a second myositis-related autoantibody. J Exp Med 160: 420-434, 1984.

34) Targoff IN, Arnett FC, Reichlin M. Antibody to threonyl-transfer RNA synthetase in myositis sera. Arthritis Rheum 31: 515-524, 1988.

35) Bunn CC, Bernstein RM, Mathews MB. Autoantibodies against alanyltRNA synthetase and tRNA ${ }^{\text {Ala }}$ coexist and are associated with myositis. J Exp Med 163: 1281-1291, 1986.

36) Targoff IN, Arnett FC. Clinical manifestations in patients with antibody to PL-12 antigen (alanyl-tRNA synthetase). Am J Med 88: 241-251, 1990.

37) Hirakata M, Nakamura $K$, Okano $Y$, et al. Anti-alanyl tRNA synthetase 
(PL-12) antibodies are associated with interstitial lung diseases in Japanese patients. Arthritis Rheum 38: S321, 1995 (Abstract).

38) Targoff IN, Trieu EP, Miller FW. Reaction of anti-OJ autoantibodies with components of the multi-enzyme complex of aminoacyl-tRNA synthetases in addition to isoleucyl-tRNA synthetase. J Clin Invest 91: 2556-2564, 1993.

39) Targoff IN, Trieu EP, Plotz PH, Miller FW. Antibodies to glycyl-transfer RNA synthetase in patients with myositis and interstitial lung disease. Arthritis Rheum 35: 821-830, 1992.

40) Hirakata M, Suwa A, Nagai S, et al. Anti-KS. Identification of autoantibodies to asparginyl-transfer RNA synthetase associated with interstitial lung disease. J Immunol 162: 2315-2320, 1999.

41) Targoff IN, Johnson AE, Miller FW. Antibody to signal recognition particle in polymyositis. Arthritis Rheum 33: 1361-1370, 1990.

42) Targoff IN, Reichlin M. The association between Mi-2 antibodies and dermatomyositis. Arthritis Rheum 28: 796-803, 1985.

43) Seelig HP, Moosbrugger I, Ehrfeld H, Fink T, Renz M, Genth E. The major dermatomyositis- specific Mi-2 autoantigen is a presumed helicase involved in transcriptional activation. Arthritis Rheum 38: 1389-1399, 1995.

44) Ge Q, Nilasena DS, O'Brien CA, Frank MB, Targoff IN. Molecular analysis of a major antigenic region of the $240-\mathrm{kD}$ protein of Mi-2 autoantigen. J Clin Invest 96: 1730-1737, 1995.

45) Mimori T, Hinterberger M, Pettersson I, Steitz JA. Autoantibodies to the U2 small nuclear ribonucleoprotein in a patient with scleroderma-polymyositis overlap syndrome. J Biol Chem 259: 560-565, 1984.

46) Habets WJ, Sillekens PTG, Hoet MH, McAllister G, Lerner MR, van Venrooij WJ. Small nuclear RNA-associated proteins are immunologically related as revealed by mapping of autoimmune reactive B-cell epitopes. Proc Natl Acad Sci USA 86: 4674-4678, 1989.

47) Craft J, Mimori T, Olsen TL, Hardin JA. The U2 small nuclear ribonucleoprotein particle as an autoantigen. Analysis with sera from patients with overlap syndromes. J Clin Invest 81: 1716-1724, 1987.

48) Mimori T, Akizuki M, Yamagata H, Inada S, Yoshida S, Homma M. Characterization of a high molecular weight acidic nuclear protein recognized by autoantibodies in sera from patients with polymyositis-scleroderma overlap. J Clin Invest 68: 611-620, 1981.

49) Mimori T, Hardin JA, Steitz JA. Characterization of the DNA-binding protein antigen $\mathrm{Ku}$ recognized by autoantibodies from patients with rheumatic disorders. J Biol Chem 261: 2274-2278, 1986.

50) Mimori T, Hardin JA. Mechanism of interaction between Ku protein and DNA. J Biol Chem 261: 10375-10379, 1986.

51) Dvir A, Peterson SR, Knuth MW, Lu H, Dynan WS. Ku autoantigen is the regulatory component of a template-associated protein kinase that phosphorylates RNA polymerase II. Proc Natl Acad Sci USA 89: 1192011924, 1992.

52) Gottlieb TM, Jackson SP. The DNA-dependent protein kinase. Requirement for DNA ends and association with Ku antigen. Cell 72: 131-142, 1993.

53) Rathmell WK, Chu G. Involvement of the Ku autoantigen in the cellular response to DNA double-strand breaks. Proc Natl Acad Sci USA 91: 7623 $7627,1994$.

54) Taccioli GE, Gottlieb TM, Blunt T, et al. Ku 80: product of the XRCC5 gene and its role in DNA repair and V(D)J recombination. Science 265 : 1442-1445, 1994.

55) Smider V, Rathmell WK, Lieber MR, Chu G. Restoration of X-ray resistance and V(D)J recombination in mutant cells by Ku cDNA. Science 266: 288-291, 1994.

56) Kirchgessner CU, Patil CK, Evans JW, et al. DNA-dependent kinase (p350) as a candidate gene for the murine SCID defect. Science 267: 1178-1183, 1995.

57) Blunt T, Finnie NJ, Taccioli GE, et al. Defective DNA-dependent protein kinase activity is linked to $\mathrm{V}(\mathrm{D}) \mathbf{J}$ recombination and DNA repair defects associated with the murine scid mutation. Cell 80: 813-823, 1995.

58) Hartley KO, Gell D, Smith GCM, et al. DNA-dependent protein kinase catalytic subunit: a relative of phosphatidyl-inositol 3-kinase and the ataxia telangiectasia gene product. Cell 82: 849-856, 1995.
59) Suwa A, Hirakata M, Takeda Y, et al. Autoantibodies to DNA-dependent protein kinase. Probes for the catalytic subunit. J Clin Invest 97: 1417$1421,1996$.

60) Reimer G, Scheer U, Peters JM, Tan EM. Immunolocalization and partial characterization of a nucleolar autoantigen (PM-Scl) associated with polymyositis/scleroderma overlap syndromes. J Immunol 137: 3802-3808, 1986.

61) Oddis CV, Okano Y, Rudert WA, Trucco M, Duquesnoy RJ, Medsger TA Jr. Serum autoantibody to the nucleolar antigen PM-Scl. Clinical and immunogenetic associations. Arthritis Rheum 35: 1211-1217, 1992.

62) Gelpi C, Alguero A, Angeles Martinez M, Vidal S, Juarez C, RodriguezSanchez JL. Identification of protein components reactive with anti-PMScl autoantibodies. Clin Exp Immunol 81: 59-64, 1990.

63) Hoshino Y, Hashimoto T, Mimori T, Akizuki M, Nishikawa T. Reccurent annular erythema associated with anti-SS-B/La antibodies. Analysis of the disease-specific epitope. Br J Dermatol 127: 608-613, 1992.

64) Rinke J, Steitz JA. Precursor molecules of both human 5S ribosomal RNA and transfer RNAs are bound by a cellular protein reactive with anti-La lupus antibodies. Cell 29: 149-159, 1982.

65) Gottlieb E, Steitz JA. Function of the mammalian La protein. Evidence for its action in transcription termination by RNA polymerase III. EMBO J 8: 851-861, 1989.

66) Scott JS, Maddison PJ, Taylor PV, Esscher E, Scott O, Skinner RP. Connective tissue disease, antibodies to ribonucleoprotein, and congenital heart block. New Engl J Med 309: 209-212, 1983.

67) Wolin SL, Steitz JA. The Ro small cytoplasmic ribonucleoproteins. Identification of the antigenic protein and its binding site on the Ro RNAs. Proc Natl Acad Sci USA 81: 1996-2000, 1984.

68) Ben-Chetrit E, Chan EKL, Sullivan KF, Tan EM. A 52-kD protein is a novel component of the SS-A/Ro antigenic particle. J Exp Med 167: 1560$1571,1988$.

69) Lerner MR, Boyle JA, Hardin JA, Steitz JA. Two novel classes of small ribonucleoproteins detected by antibodies associated with lupus erythematosus. Science 211: 400-402, 1981.

70) O'Brien CA, Wolin SL. A possible role for the $60-\mathrm{kD}$ Ro autoantigen in a discard pathway for defective $5 \mathrm{~S}$ rRNA precursors. Genes \& Development 8: 2891-2903, 1994.

71) Davies DJ, Moran JE, Niall JF, Ryan GB. Segmental necrotizing glomerulonephritis with antineutrophil antibody. Possible arbovirus aetiology? Br Med J (Clin Res Ed) 285: 606, 1982.

72) Jennette JC, Falk RJ, Andrassy K, et al. Nomenclature of systemic vasculitides. Proposal of an international consensus conference. Arthritis Rheum 37: 187-192, 1994.

73) Cohen TJW, van der Woude FJ, Fauci AS, et al. Association between active Wegener's granulomatosis and anticytoplasmic antibodies. Arch Intern Med 149: 2461-2465, 1989.

74) Gross WL. Antineutrophil cytoplasmic autoantibody testing in vasculitides. Rheum Dis Clin North Am 21: 987-1011, 1995.

75) Falk RJ, Jennette CJ. Antineutrophil cytoplasmic autoantibodies with specificity for myeloperoxidase in patients with systemic vasculitis and idiopathic necrotizing and crescentic glomerulonephritis. N Engl J Med 318: $1651-1657,1988$.

76) Endo H. Hosono T, Kondo H. Antineutrophil cytoplasmic autoantibodies in 6 patients with renal failure and systemic sclerosis. J Rheumatol 21: 864-870, 1994.

77) Sobajima J, Ozaki S, Osakada F, et al. Novel autoantigens of perinuclear anti-neutrophil cytoplasmic antibodies (P-ANCA) in ulcerative colitis. Non-histone chromosomal proteins, HMG1 and HMG2. Clin Exp Immunol 107: 135-140, 1997.

78) Hughes GR, Harris NN, Gharavi AE. The anticardiolipin syndrome. J Rheumatol 13: 486-489, 1986.

79) Matsuura E, Igarashi Y, Yasuda T, Triplett DA, Koide T. Anticardiolipin antibodies recognize $\beta 2$-glycoprotein I structure altered by interacting with an oxygen modified solid phase surface. J Exp Med 179: 457-462, 1994.

80) Mimori T, Suganuma K, Tanami Y, et al. Autoantibodies to calpastatin (an endogenous inhibitor for calcium-dependent neutral protease, calpain) 


\section{MIMORI}

in systemic rheumatic diseases. Proc Natl Acad Sci USA 92: 7267-7271, 1995.

81) Despres N, Talbot G, Plouffe B, Boire G, Menard HA. Detection and expression of a cDNA clone that encodes a polypeptide containing two inhibitory domains of human calpastatin and its recognition by rheumatoid arthritis sera. J Clin Invest 95: 1891-1896, 1995.

82) Christensen ML, Pachman LM, Schneiderman R, Patel DC, Friedman JM. Prevalence of Coxsackie B virus antibodies in patients with juvenile dermatomyositis. Arthritis Rheum 29: 1365-1370, 1986.

83) Query CC, Keene JD. A human autoimmune protein associated with U1 RNA contains a region of homology that is cross-reactive with retroviral p30 gag antigen. Cell 51: 211-220, 1987.

84) Maul GG, Jimenez SA, Riggs E, Ziemnicka-Kotula D. Determination of an epitope of the diffuse systemic sclerosis marker antigen DNA topoisomerase I. Sequence similarity with retroviral p30 $0^{\text {gag }}$ protein suggests a possible cause for autoimmunity in systemic sclerosis. Proc Natl Acad Sci USA 86: 8492-8496, 1989.

85) Reeves WH, Sthoeger ZM. Molecular cloning of cDNA encoding the p70 (Ku) lupus autoantigen. J Biol Chem 264: 5047-5052, 1989.
86) Kohsaka H, Yamamoto K, Fujii H, et al. Fine epitope mapping of the human SS-B/La protein. Identification of a distinct autoepitope homologous to a viral gag polyprotein. J Clin Invest 85: 1566-1574, 1990.

87) Walker EJ, Jeffrey PD. Polymyositis and molecular mimicry, a mechanism of autoimmunity. Lancet 2: 605-607, 1986.

88) Walker EJ, Jeffrey PD. Sequence homology between encephalomyocarditis virus protein VP1 and histidyl-tRNA synthetase supports a hypothesis of molecular mimicry in polymyositis. Med Hypotheses 25: 21-25, 1988.

89) Ge Q, Trieu EP, Targoff IN. Primary structure and functional expression of human glycyl-tRNA synthetase, an autoantigen in myositis. J Biol Chem 269: 28790-28797, 1994

90) Fatenejad S, Mamula MJ, Craft J. Role of intermolecular/intrastructural B- and T-cell determinants in the diversification of autoantibodies to ribonucleoprotein particles. Proc Natl Acad Sci USA 90: 12010-12014, 1993.

91) Dong X, Hamilton KJ, Satoh M, Wang J, Reeves WH. Initiation of autoimmunity to the $\mathrm{p} 53$ tumor suppressor protein by complexes of $\mathrm{p} 53$ and SV40 large T antigen. J Exp Med 179: 1243-1252, 1994. 